\title{
Calcified Chronic Subdural Haematoma Mimic Meningioma
}

\author{
Khalid Bin Madhi*, Ghaleb Awadh \\ Hadhramout University, Mukalla, Yemen \\ Email: *aboomara1000@yahoo.com
}

How to cite this paper: Madhi, K.B. and Awadh, G. (2019) Calcified Chronic Subdural Haematoma Mimic Meningioma. Open Journal of Modern Neurosurgery, 9 , 457-460.

https://doi.org/10.4236/ojmn.2019.94044

Received: August 23, 2019

Accepted: October 25, 2019

Published: October 28, 2019

Copyright $\odot 2019$ by author(s) and Scientific Research Publishing Inc. This work is licensed under the Creative Commons Attribution International License (CC BY 4.0).

http://creativecommons.org/licenses/by/4.0/

\begin{abstract}
Background: The calcified chronic subdural haematoma is rare. The first case description is in 1884 [1]. The incidence of calcified chronic subdural haematoma has been reported to be $0.3 \%$ to $2.7 \%$ of all chronic subdural haematoma. Case Description: We reported a case of 27 year-old male presenting with deterioration of motor function in his right limbs since 1 month before admission, and brain imaging C-T scan and MRI were done; pathological lesion was successfully and completely removed, with good improvement post-surgery.
\end{abstract}

\section{Keywords}

Calcified Chronic Subdural Hematoma, Meningioma, Outcome, Surgical Treatment

\section{Introduction}

Calcified chronic subdural hematoma (CCSH) is rare, the first case description is in 1884 . The incidence of CCSH has been reported to be $0.3 \%$ to $2.7 \%$ of all CSH [1] [2]. There are about 100 cases of (CCSH) published. The optimal surgical procedure for this type of lesion, classically referred to as "armored brain", has not been agreed upon due to the insufficient reexpansion of the brain after surgery [2] [3].

Calcified chronic subdural haematoma $(\mathrm{CCSH})$ is a challenging disease as regarding diagnosis and management.

\section{Case Report}

A 27-year-old male had gradual onset Rt. Hemi paresis one month before admission. 
With history of evident trauma fifteen years ago and history of right focal epilepsy, on admission patient was fully conscious; the muscle power was grade 3/5 on Rt. Lower limb and grade 4/5 on Rt. upper limb.

CT brain and MRI brain were done. All radiological reports reveal extradural lesion mainly calcified haematoma with differential diagnosis:

- A Typical meningioma;

- Bone Tumors, as shown in Figure 1.

\section{Interaoperative Finding:}

Under general anaesthesia with supine position, left frontal skin and left craniotomy were done. We found no exteradural lesions while we palpated dura and found subdural mass. Dural flap was created with meticulous dissection done and total removal of hard mass which has outer grey to red outer surface and whitish inner surface which show multiple calcifications and imprint over cortical surface of the brain as shown in Figure 2 and Figure 3.
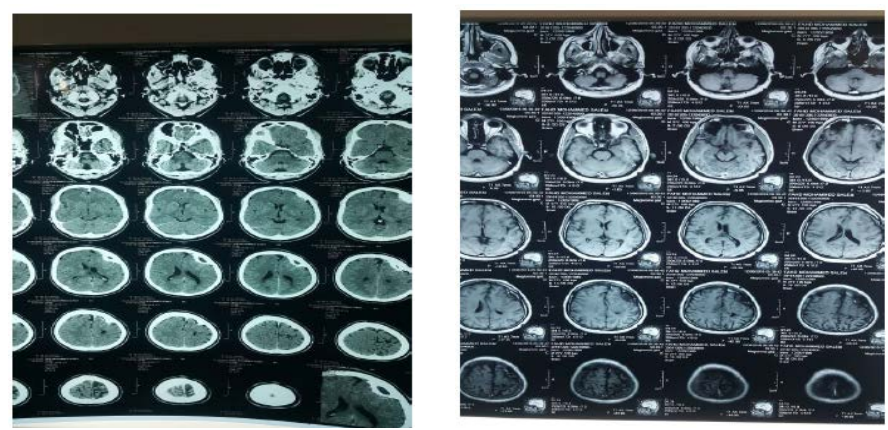

Figure 1. Brain C-T scan and MRI show the lesion.
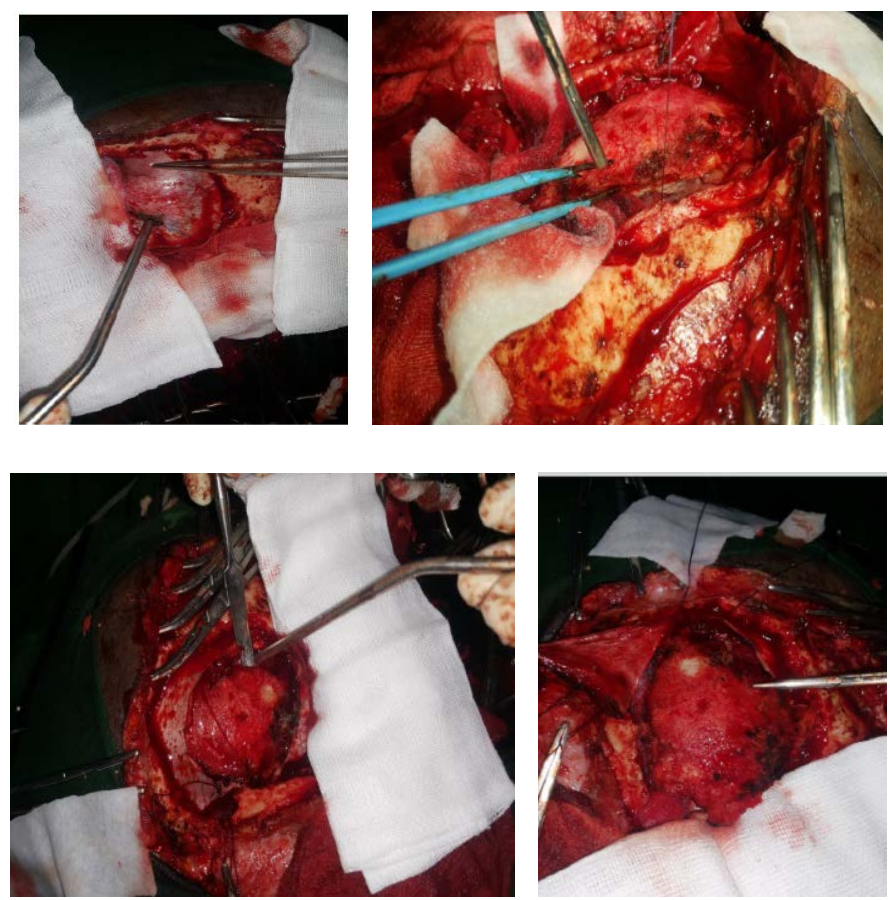

Figure 2. Intraoperative finding. 
Haemostasis was done using bipolar diathermy and surgicel.

Dural repair was done, repositioning of bone flap and closure of wound in layers with suction drain.

\section{Post-operative:}

First day post-operative patient improved and started to walk without support; then day by day patient feels he is better. Then patient has been followed for one month with complete clinical improvement. Consent was taken from patient for case report publication.

\section{Histopathology:}

Calcified hematoma is shown in Figure 4 in pictures A and B. Histopathological picture (a) hemorrhage in the center with fibrous tissue at right; Picture (b) demonstrated calcification (arrow).
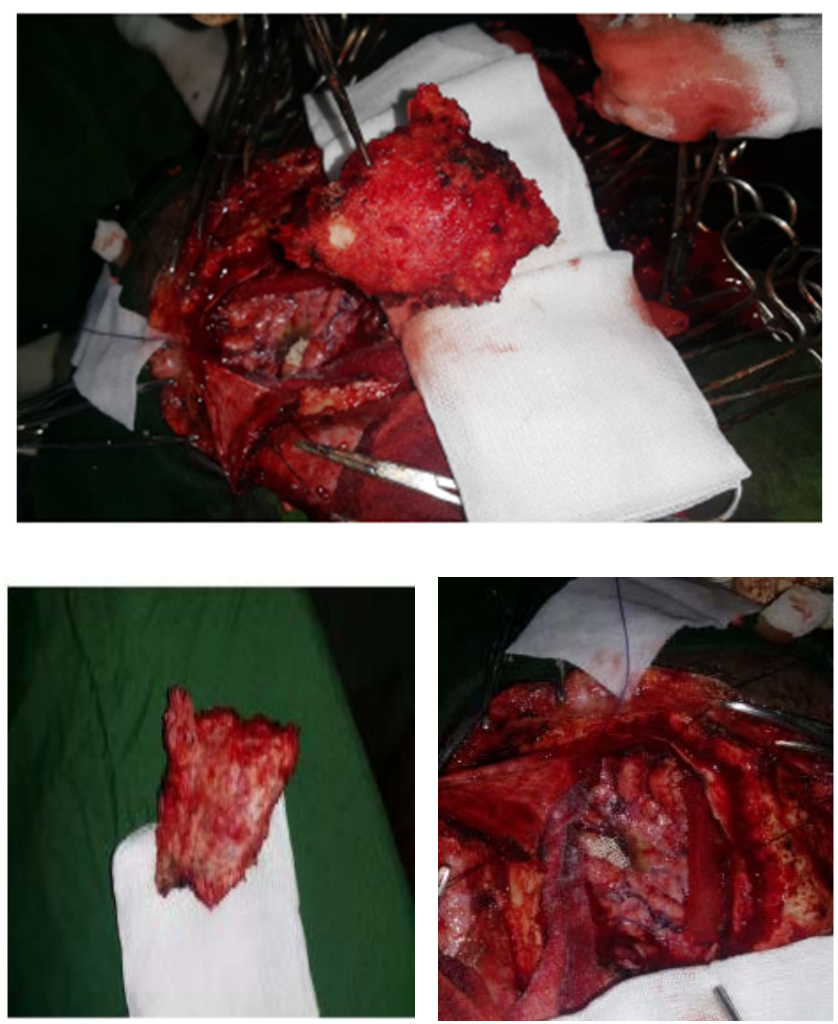

Figure 3. During removing of calcified lesion.

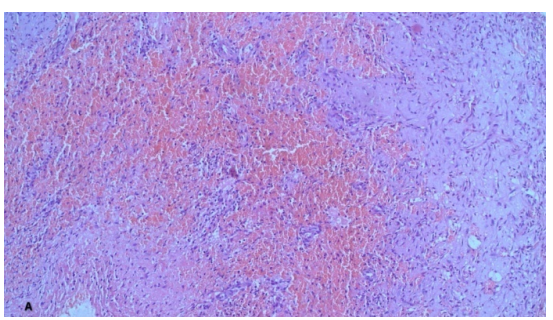

(a)

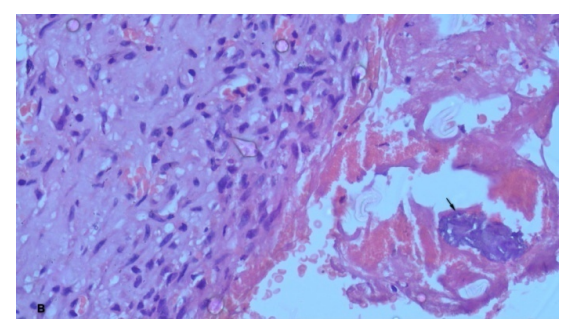

(b)

Figure 4. (a) Hemorrhage in the center with fibrous tissue at right; (b) Demonstrated calcification (arrow). 


\section{Discussion}

It is unclear how calcification occurs and develops in a CCSH; nonetheless $\mathrm{CCSH}$ may evolve slowly through the process of hyalinization into calcification and eventually ossification. This process may take 6 months or many years to occur [4] [5]. This agrees with time of calcification in our patient. He gives history of head trauma before 15 years.

CCSH may be manifested with seizures. Some patients are symptomatic in spite of layers of haematoma [5]. Also our patient gives history of convulsion focal in type since many years in Rt. Side only and he treated from it by traditional method. Cauterization of pectorals muscle in Lt. side but disagrees with other paper which recorded mental retardation \& physical and brain atrophy as effect CCSH [1] [5].

The Dura mater may tightly adherent to CCSH and cortex. The dissection from brain may cause contusion or bleeding [5]. Therefore, removal of this lesion has not been necessary beneficial [1].

The surgical intervention is favored for progressively enlarged CCSH.

In recent years successful removal of calcified CSH with good neurological recovery had been reported in sporadic cases [3].

\section{Conclusion}

We report this case considered as rare cranial lesions with neurological deficit which may mimic tumors. After revision of literature and our experience with this reported case we recommend surgical treatment in these patients, resulting in good surgical outcome.

\section{Conflicts of Interest}

The authors declare no conflicts of interest regarding the publication of this paper.

\section{References}

[1] Yan, H.J., Lin, K.E., Lee, S.T. and Tzaan, W.C. (1998) Calcified Chronic Subdural Hematoma: Case Report. Chang Yi Xue Za Zhi, 21, 521-525.

[2] Niwa, J., Nakamura, T., Fujishige, M. and Hashi, K. (1988) Removal of a Large Asymptomatic Calcified Chronic Subdural Hematoma. Surgical Neurology, 30, 135-139. https://doi.org/10.1016/0090-3019(88)90099-7

[3] Pappamikail, L., Rato, R., Novais, G. and Bernardo, E. (2013) Chronic Calcified Subdural Hematoma: Case Report and Review of the Literature. Surgical Neurology International, 4, 3-6. https://doi.org/10.4103/2152-7806.107548

[4] Kaplan, M., Akgün, B. and Seçer, H.I. (2008) Ossified Chronic Subdural Hematoma with Armored Brain. Turkish Neurosurgery, 18, 420-424.

[5] Oda, S., Shimoda, M., Hoshikawa, K., Shiramizu, H. and Matsumae, M. (2010) Organized Chronic Subdural Haematoma with a Thick Calcified Inner Membrane Successfully Treated by Surgery: A Case Report. Tokai Journal of Experimental and Clinical Medicine, 35, 85-88. 